\title{
Opportunities and challenges facing NGOs using sport as a vehicle for development in post-apartheid South Africa
}

\author{
Ben Sanders, Julie Phillips and Bart Vanreusel
}

\begin{abstract}
Post-apartheid South Africa manifests poor social indicators with over half the population living below the poverty line and the worst levels of inequality in the world, with much work needed to overcome the skewed legacy of apartheid. Sport suffered in this system resulting in unequal access to sporting facilities and opportunities, meaning many South Africans cannot exercise their right to play. Despite this legacy, sport can fulfil a vital developmental role in alleviating some of these issues. The state has a major role to play but it must be supported by civil society and non-governmental organisations (NGOs) who have the ability to deliver in situations where government has struggled. This article researches the opportunities and challenges NGOs encounter when using sport for development within the education system, in post-apartheid South Africa. This study used a qualitative approach to collect data on the opportunities and challenges encountered by two NGOs based in Cape Town that use sport as a means of development, but in markedly different ways. The study suggests that NGOs face a variety of conceptual, technical, logistical and organisational challenges using sport in schools and should enact certain measures to reduce resistance from educators and ensure successful programmes. The interaction between NGOs, schools and the state Department of Education is a complicated process that presents obstacles and opportunities. Nevertheless, despite these challenges it is clear NGOs can support schools in South Africa to optimise their physical activity programmes in the backdrop of a stagnating education system and a lack of sporting support from the government. NGOs in an educational setting such as schools operate in what Houlihan has identified as a crowded policy space. Yet, the observations in this study suggest that, particularly in the context of education, a partnership policy model of NGO work is preferred.
\end{abstract}

\section{Introduction}

Sport is widely regarded as a means of development and for its contribution to attaining the Millennium Development Goals, a far cry from the past when it was seen merely as a form of recreation (Van Eekeren, 2006, p. 1; Lindsey \& Banda, 2011). Participating in sport has proven intrinsic benefits but it also provides extrinsic value as it can facilitate the development of education, health and peace amongst other social issues. Many national and international actors now see sport 
as a development tool and indeed a number of policy initiatives have highlighted the potential contribution of sport to development efforts (Beutler, 2008). The United Nations (UN) established an Inter-Agency Task Force on Sport for Development and Peace in 2002 and passed Resolution 58/5 entitled 'Sport as a means to promote education, health, development and peace' (United Nations Inter-Agency Task force on Sport Development and Peace, 2003, p. 5). Furthermore, the first Magglingen Conference in 2003 set the stage as international agencies and states signed a declaration affirming their commitment to sport and development and 2005 was the International Year of Sport and Physical Education (Van Eekeren, 2006, p. 4). As such, sport is now prominent on donor agendas and has assumed a higher profile in development circles.

Despite the recent advances, the use of sport in social development has a long history. Kidd (2008) traced it back to the recreation interventions aimed at improving middle- and working-class Englishmen in the late nineteenth century. Kidd concludes however that the present display of social development through sport is different in the scale and scope of agencies and organisations involved, as well as the degree of financial support from powerful international agencies and federations. The increased interest in sport-for-development has precipitated some research though much of it remains emerging and anecdotal. As Van Eekeren (2006, p. 1) claims: 'Until recently, research into sport was tantamount to academic suicide' but now there is increasing knowledge of sport as a medium of development, not only from sports administrators but also in fields as diverse as health, education, governance and the environment. However, sport-for-development remains a newly emerging field and while research has grown it remains limited. Lindsey and Banda (2011) further highlighted that most of the research in this domain is characterised by its international perspectives. Others argue (Hayburst \& Frisby, 2010) that sport- for-development research has been dominated by the Global North, meaning actors from the Global South have yet to be fully included in this 'neo-colonial' process of development.

A fundamental part of development is education, worldwide and particularly in South Africa with its high unemployment and lack of skilled workers. Sport is seen as a natural and vital component of education and can function as a 'school for life' by instilling values and life skills among youth (United Nations, 2003). However, these wide-ranging, almost universal claims must be treated with some caution. Sport does not automatically result in social change or an improvement in the education system or holistic development of youth. While sport can have positive micro-impact on individuals this does not necessarily lead to greater outcomes in the community (meso) and society (macro). The right conditions need to be in place for sport to successfully stimulate development and education, and even then nothing is guaranteed. Coalter (2010) contends that social capital or local cooperation cannot nullify greater macro issues, such as lack of resources, political support and the socio-economic situation. Furthermore, it is short-sighted, naïve and dangerous to claim that sport can change these overall structures since the effects of sport are not as concrete as the rhetoric suggests. We need to 
understand the potential benefit of sport but also the harmful effects, as like any other activity, sport is not inherently good or bad. Coalter (2010) thus concludes that a major weakness of sports programmes is that they are 'seeking to solve broad gauge problems via limited focus interventions'.

\section{The rise of sport for development NGOs}

The emergence of NGOs with a focus on sport-related programmes is a rather new phenomenon. NGOs with a specific sport-related objective originated in the late $1990 \mathrm{~s}$ and beginning of the twenty-first century. The first such NGO, Mathare Youth Sport Association (MYSA) started in 1987 in Kenya (Van Eyken, 2010) and now commands over 25,000 participants. Non-governmental involvement in sport for development has increased dramatically. There are now 389 sport and development related organisations listed on the 'International Platform on Sport and Development' (http://www.sportanddev.org). Van Eyken's (2010) research demonstrates that the most drastic increase in NGOs with sport-related programmes has occurred during the twenty-first century. Between 1985 and 2000 about 30 organisations were in existence but by 2010 there were more than 110 recorded organisations, a remarkable shift.

Although the intervention of NGOs in sport and physical activity for youth is a relatively recent phenomenon, the number of NGO-led initiatives is growing rapidly worldwide. At the 2011 Beyond Sport Summit in Cape Town, South Africa, hundreds of NGOs from all continents were seeking partnerships in order to establish sport programmes for the underserved. Three hundred and fifty-six NGOs worldwide submitted sport-related projects in order to be eligible for the Beyond Sport Awards. In contrast to this innovative growth, little research has been done on the impact of these new players in the policy field of youth sport and physical education (PE).

In general, sport policies are generated by an interaction between government initiatives, market initiatives and civil action. NGOs hold an atypical role in this policy interaction. NGOs intervene when this interaction partially or generally fails to produce expected initiatives and outcomes. From this perspective, sportrelated NGOs emerge as a response to sport policies that fail to deliver expected programmes.

\section{Sport and education}

In the context of education, the role of NGOs is even more delicate. Whereas education is essentially a priority task of local and national governments, the emergence of NGOs in an educational context suggests that public policy on education at least partially fails to meet its objectives and that civil society organisations are needed to fill the gap. Sport-related NGOs with a focus on education operate in an area that is a primary concern for governments. This atypical policy interaction has received little attention in sport policy research to date. 
This study on the emerging role of NGOs in school programmes on PE fits within changing and debated policies and practices in providing physical activities in an educational context, conceptualised by Houlihan (2000) as a 'crowded policy place'. Authors such as Houlihan and Green (2006), Flintoff (2003) and Macdonald et al. (2008) have pointed out a multitude of interests, ideologies and programmes offering school-based physical activities from traditional state intervention in PE curricula to market-driven neoliberal initiatives in catering for school sport. However, the rise and specific role of NGOs in this process has received only marginal attention in this debate.

However, Houlihan's (2000) observation that PE and sports are policy spaces that were already crowded if not congested doesn't seem as relevant to South Africa and most other African countries. On the contrary, in many African countries, schoolbased PE seems to be an under attended or almost empty policy space with NGOs (acting as private initiatives) trying to fill the policy gap. This epitomises the difficulty of applying north-driven ideas and solutions to the developing world without first contextualising the problem.

Flintoff (2003, p. 231) argues that the central premise of school sport initiatives is the strategic development of networks and partnerships to maximise the quality, quantity and the coherence of youth sport and PE opportunities. In the context of post-apartheid South Africa, schools can be seen as an arena in which a complex range of interests attempt to assert control over policy (Houlihan, 2000, p. 171). NGOs are seen as relatively new players in this arena. This study on NGOs catering for sport and PE aims to elaborate on Flintoff's (2003) observation, in the specific context of South Africa, and contribute more generally to understanding the role, legitimacy and policy of sport and physical activity in a context of development.

\section{South Africa - the case for sport}

Post-apartheid South Africa manifests poor social indicators with over half the population living below the poverty line, unemployment estimated at $22.9 \%$ and approximately $18 \%$ of adults infected with HIV/AIDS (CIA, 2010). Life expectancy is estimated to be only 49 and South Africa has recently overtaken Brazil as 'the most consistently unequal country in the world' with a Gini coefficient index of 0.679 (Bhorat et al., 2009). While sport and physical activity cannot solve these problems alone, it may play a positive developmental role (Keim, 2010, p. 2). Sport-fordevelopment is especially topical in South Africa given the recent 2010 World Cup (Pillay, et al., 2009, p. 5). This mega-event spawned much interest in sport with many development initiatives across the country using sport as a vehicle for social change.

But before we map a role for sport in South Africa, one needs to examine the potential of sport in achieving development. A detailed exploration and comparison of sports development programmes in an educational context will prove useful. Improved understanding of the challenges facing NGOs in this sector will add knowledge to government and civil society and may enhance service 
delivery (Keim, 2009, p. 33). While there is much literature on the way sport can promote development, there is little reference to obstacles that hamper this approach in South Africa. Starting from the premise that sport can promote education, if applied in the right manner; the current study seeks to fill some gaps in the literature by gathering empirical data on the challenges facing sport in the education system. This research centres on two NGOs working within the education system and examining the challenges they encounter. The research deals mainly with work in the Western Cape, though the findings do have relevance for South Africa and the continent, as well as broader policy implications for the relationship between education and sport worldwide.

\section{Working with the state - to partner or not to partner?}

Preliminary investigations reveal that integration with government is a doubleedged sword for many NGOs, both an opportunity and a challenge (Kaufman, 2009). While partnerships with the state can help these organisations widen the scope of their work, access funding and become more sustainable, they can also lead to dependency on government, an inordinate amount of bureaucracy and may even hamper the development work itself (Cooper, 2009). While the state offers more stability than alternative sources of funding, it does compromise private initiative and creativity, leading to sport becoming entangled with politics (Van Eekeren, 2006, p. 10). Of course sport is not totally 'free of politics' as former International Olympic Committee (IOC) chairman Avery Brundage so boldly stated over 50 years ago (Cashmore, 1990). This is nowhere more evident than South Africa, which endured sports boycott during apartheid and has since put sport at the forefront of state policy, hosting mega-events such as the 2010 World Cup and developing an agenda and scorecard for transformation in sport. But it does become increasingly difficult to achieve outcomes when sport is expected to conform to government policy.

Sport has the potential to contribute to development of the new South Africa, but what should its role be? It can make a significant contribution to education, but how can this be realised? The potential value of sport in education explains the recent attempts to re-introduce and raise the profile of PE in schools since it has been marginalised in recent times, seen as a luxury due to its non-academic nature. This is illustrated by a far-reaching analysis of 126 countries which showed that the status of PE has dropped in almost all states surveyed (Hardman \& Marshall, 1999) leading to a lack of sports activity and increase in health risks. This is nowhere more relevant than in South Africa where PE was replaced as a stand-alone subject in 2004 by Life Orientation (LO) within South Africa's National Curriculum (Draper et al., 2010).

Physical development and movement is listed as one of the four learning outcomes of LO, along with health promotion, social development and personal development. However, the majority of teachers are not equipped to deliver PE and are not trained in sports science and lack basic skills such as First Aid. Furthermore, the current LO training only provides one teaching hour on physical 
development and movement per week, hardly enough to equip teachers for the challenges they face in schools.

The South African government has recognised that PE needs to be revived in schools and the Department of Sport and Recreation and Department of Basic Education (2011) have both made a firm commitment to develop an integrated school sport framework that includes the integration of $\mathrm{PE}$ and sports participation into the school day. It is only recently that this debate on school sport and PE has taken centre stage in South Africa, reaching what Houllihan (2000) previously described as a 'crowded policy space'.

It is clear the state has a major role to play in both the development of sport itself and in using sport-for-development but it needs to be supported by NGOs and other organs of civil society who have shown an ability to deliver in situations where government has struggled. And for these organisations to realise the potential of sport as a development tool in the realm of education, there needs to be an in-depth, critical enquiry into the range of challenges and opportunities they face in South Africa.

\section{Methods}

This study used a qualitative approach to collect data on the opportunities and challenges encountered by NGOs in Cape Town, South Africa that use sport as a means of development. A case study design has been chosen since it will offer field level insight, showing how specific sports programmes work in specific contexts as argued by Cronbach (1975). By focusing on a case, one can 'uncover the interaction of significant factors characteristic of the phenomenon' (Merriam, 1998, p. 29). Two NGOs working with schools in the Western Cape Province constituted the cases. While there are many NGOs working in this field, these two have been chosen for the different approaches that they have adopted. The first NGO is a high-profile international organisation founded in 2002 that uses its curriculum to educate youth about HIV/AIDS through soccer. Headquartered in Cape Town, South Africa, it operates across Africa as it has formed strategic partnerships with local organisations, optimising their ability to reach African youth (Grassroot Soccer, 2010). The NGO operates predominantly during school hours in South Africa, with classes forming part of the LO curriculum which all learners are obliged to attend. The organisation thus has to conform closely to school times, policies and procedures.

The second NGO is a smaller organisation founded in 1997 and acts as an intermediary between schools and government, facilitating the provision of extramural activities to disadvantaged schools. Its goal is 'to help South African schools develop into hubs of lifelong learning, recreation and support, for both their school-going and surrounding communities' (Extra-Mural Education Project, 2009). It is also based in Cape Town but only operates locally in the Western Cape. This NGO runs seminars with staff from schools, training them to provide extramurals, ranging from sport to arts and crafts, extra lessons, music etc. The NGO does not run the extra-murals but provides training, co-ordination and 
evaluation. Furthermore, it is not focused exclusively on sport, unlike the first NGO in this study, which is limited to soccer, but takes a holistic approach, with a range of activities for learners, parents and community members. This NGO has partnered with the Western Cape Education Department (WCED) and the subsequent funding has allowed them to broaden their network considerably.

Individual in-depth interviews were conducted with the researchers at each NGO, assistant site-coordinator and community project-coordinator, programme interns, development practitioners, heads of sport at schools and/or LO coordinator and school principals. Furthermore, a focus group discussion was conducted with eight coaches and another with approximately 20 teachers. An interview guide was used to ensure that the questions and themes generated were relevant to the participants and the research itself.

The analysis of the interviews started with the transcription of information from audio-tape recordings. Data were transcribed verbatim to ensure that it is conveyed as genuinely as possible by the researcher, with no attempt to modify the findings or set a certain agenda. Independent perspectives were obtained by asking an independent researcher for his views on the transcripts. This process ensured a clear correlation between the reality experienced by the participants and the information presented. Analysis was done by reading through the transcripts several times, making as many headings as necessary to describe all aspects of the contents.

In addition, grouping of the themes into broader categories helped to reduce the number of themes. Both pre-determined and emerging themes were noted, making a concerted effort to ensure that respondents do not merely answer questions but provide their own perspective on challenges. During the interview process the same themes were raised, showing that the research had reached the point of saturation.

The data from the interviews were complemented and contextualised with data from documents and observations. The documents included letters, minutes of meetings, evaluations and external reports of the NGOs. However, most of these documents were produced internally, mainly for monitoring and evaluation purposes and have their limitations. Furthermore observations, to experience firsthand how these sports projects operate within the education system, were included. These observations provided insight into the participants' experience of the programmes. A number of observation sessions occurred at each site, so the common practices were recorded, as opposed to a once-off viewing. Observation was accompanied by reports from the schools and NGOs involved, so the reality observed can be contrasted with the written theory.

This mixed method approach was used in order to minimise the observation bias and improve the reliability and validity of the observation. The observer is not formally or informally linked to the work of the chosen NGOs. 


\section{Results}

It was clear from the research that both NGOs faced a broad range of challenges using sport-for-development in schools. Certain challenges were common while others were not. Even more importantly, while the findings are based on a study of just two non-profit organisations and one cannot generalise widely, there may be an element of truth for organisations of a similar nature. Even government would do well to heed the results when it comes to reviewing its policy on sport in schools. Thus while the two NGOs are markedly different as illustrated in Table 1 this should be seen as a strength of research, as the findings may be relevant for a greater range of actors, especially in the sport-for-development field which boasts a genuine diversity and depth of organisations.

Relationship between NGOs, government and schools

These challenges are perhaps the most important and relate to the way in which the organisations (NGOs), schools and the relevant government departments under- stood each other. The smaller, locally based NGO had developed a partnership with government (The Western Cape Education Department) to promote extra-murals and turn schools into community hubs. No formal partnership existed between the larger international NGO and government but the organisation was seeking to get its curriculum approved by the Department of Education. Both these NGOs did however experience difficulties with the government, but despite these they were committed to working with government and clearly believed that the benefits of any partnership far outweighed the disadvantages. It is thus important to examine these relationships in detail. Furthermore, it is vital to interrogate the relationship between the schools and government. Kidd (2008) has suggested that because of the problematic issues evident in the relationship between NGOs and states, a concerted effort should be made to strengthen state capacities in the South. Irurzun-Lopez and Poku (2005) however draw attention to the fact that political competition and a lack of resources weaken the relationship between states and NGOs. 
Table 1. Differences between the two NGOs

NGO 1

NGO 2

Large, international organisation

Works across Africa and Latin America

Only urban schools in Cape Town area

Use sport-for-development in schools

Only soccer and HIV/AIDS education

Developed a specific Curriculum

Delivers curriculum to learners

Works only with Grades 6-9 (teenagers)

Works mainly during $\mathrm{LO}$ classroom hours

Delivers the curriculum itself through coaches

Pays coaches for delivering the curriculum

Independent of state, funded by external donors
Small, locally based organisation

Works only in the Western Cape, South Africa

Urban and Rural schools in Western Cape

Use extra-murals for development in schools

Extra-murals include a range of sports and activities

Developed a range of training sessions

Delivers training to teachers/educators

Seeks to benefit all levels of school youth

Promotes extra-murals - usually after hours

Does not deliver - trains teachers to deliver

Does not pay teachers, but offers skills training

Partnership with state, Western Cape Education

Department

The smaller, locally based NGO was initially independent of the state but had since worked with government departments as its extra-mural project (Continued Development Programme) was approved by the WCED. While this partnership allowed the NGO to expand and gain access into the education system, it meant that the organisation was somewhat dependent on government. The NGO had to show that its interventions resonated with the WCED's nine key focus areas of whole school development. The extra-mural programme was essentially a partnership between the NGO and the WCED, though it is the NGO that was most often (and incorrectly) seen as the owner or lead partner. Furthermore by always assuming a lead role, and branding the programme as that of the NGO, the organisation almost ignored, or negated, the role of the state. In reality, the schools targeted were the responsibility of the WCED and the programme was a partnership, not NGO owned with government support. As a result, it became clear to most government officials that the partnership was not really working. Both sides were to blame and this malaise obviously contributed to the end of state funding.

Furthermore, it is important to note that the political landscape affected the NGO's relationship with the state even more. The Democratic Alliance (DA) replaced the African National Congress (ANC) as the ruling party in the Western Cape after the 2009 elections, leading to many proponents of the NGO being replaced by more sceptical politicians. This drastic shift even led to concerns that the existing agreement between the NGO and the state would not be honoured. While these fears were unfounded, the organisation realised it would be futile to apply for further funding:

The DA replaced the ANC last year (2009) and the new education department does not like NGOs. Our big supporters like Naledi Pandor (former Minister of Education) are gone. We knew there was no point in trying to renew the contract 
because we work with district officials and they told us. So we need new funding. Maybe in 2 years' time, the ANC will be back in power and we will start again. Who knows? (Cooper, 2009)

As part of the change of the ruling party in the Western Cape, new directors were appointed with subsequent changes to policies. An increased focus on literacy and numeracy and on the improvement of Grade 12 results were some changes that resulted in extra-mural activities being marginalised and the NGO suddenly found themselves out of favour with the new regime. In response, the NGO modified their intervention and made a concerted attempt to link it to the Education department's nine key focus areas of whole school development.

As mentioned earlier, the large international $\mathrm{NGO}$ is mainly funded by international donors and operated independently of government. But on examination of the relationship between this NGO, government and schools, most schools indicated it was easier and more effective partnering with the NGO. Most teachers were critical of the Department of Education and felt they did not provide enough support or training. The LO co-ordinators in particular felt let down by the department and were disillusioned with the state:

They send subject advisors to our school, to check our sessions and give advice. But I cannot say they help. They speak more than doing. (LO Co-ordinator, Primary School, Khayelitsha)

LO co-ordinators agreed that it was such NGOs that 'were doing things' but the government was just 'talk, talk, talk'. They also complained that while there were workshops for other subjects (e.g. Maths and Science), there were no workshops for LO. Again it appeared that the state did not regard LO as an equal partner in the school syllabus.

The relationship between the large international NGO and government was clearly evolving and there was a possibility that they may have formed a partnership. In addition it is important to note that with the political changes, and changes in donor funding and requirements, the nature of the relationship with state departments (and which departments) changes markedly over time.

While these two NGOs, and other similar organisations, must be commended for having helped schools provide and manage their sporting activities in the light of a lack of sporting support from the state, they must not assume the same role as government. These organisations do not have the same capacity as the state and are dependent on government in some form or another. While NGOs may be more flexible and responsive and have shown an ability to deliver in situations where the state has struggled, they cannot, and must not, take over government's service delivery role. Rather NGOs and other such organisations should provide advocacy and support to state departments, and explore alternative avenues for co-operation. 
There are number of different policy models in which NGOs can perform their work. While many NGOs adhere to an intervention policy model, working independently of local authorities, this may result in organisations competing with one another and the state for resources. Forming partnerships with local authorities and aligning with government directives may be more complicated and convoluted but will ultimately ensure shared strategic objectives and more sustainable outcomes.

Lindsey and Banda (2011) highlighted that the relationships between governments and NGOs have been interrogated recently and some authors (Irurzun-Lopez \& Poku, 2005) believe this could be due to political competition and a lack of resources. Apart from the strained relationship between government and these NGOs, competing with other organisations is another challenge faced by NGOs. This competition has also been highlighted by other authors (Amstrong, 2004; Webb, 2004; Kidd, 2008). In this case it was reported that an international NGO not dissimilar to the one included in this study that 'uses media, pop culture, music, theatre and sports to stop the spread of HIV/AIDS' (Youth Aids: Our Mission, 2010) was working at one of their partner schools. In fact the coaches reported one instance in which a communication mix-up meant both organisations were set to use the same class period for their work.

Kidd (2008) has warned that competing NGOs should focus on strengthening the state programmes on health and education instead of competing for funding and placement for volunteers. Officials from both NGOs admitted that partnering with government was a catch-22 situation as it may empower them with funding and resources but may limit their independence and lead to a great deal of bureaucracy and even conflict. While the two NGOs included in this study reported differing relationships with government, both organisations realised the need to work with state organs in order to access sustainable funding and broaden the scope of their work. Perhaps they realise as Coalter (2010, p. 306) states 'they are not simple substitutes for the state, and can only really thrive to the extent that the state actively encourages them'.

\section{Organisational challenges}

Both NGOs included in this study are confronted with many organisational challenges, from the difficulties of working within the school structure to the numerous complaints provided by coaches about a lack of logistical support. Furthermore, schools are often critical of the relevant organisation for not providing enough genuine support and evaluation of their projects. At one primary school, a teacher complained the relevant NGO virtually disappeared and he cannot remember their last meeting, hardly a good sign. This is illustrated by the quote below:

We hardly see them anymore. Our last meeting was planned for last year, but it was cancelled. It is like they came here and promised to help us and we got excited about it. But then they just left again and it is the same. (Primary School Teacher) 
Similarly most of the schools surveyed professed a desire for regular feedback from the large, international NGO. At the end of each curriculum, learners do complete a questionnaire which provides the organisation with an idea of the progress they have made. However, somewhat bizarrely, these results are usually not communicated to the schools themselves. It would be useful for teachers to understand the progress students are making through the curriculum designed by the NGO and how this links with their classroom subjects. It would also help the NGO cement their position in schools if educators are aware of the benefits of the programme:

Just one thing I am asking for is the assessment. We need to know the learners' problems so we can help them. Also if they (the NGO) can show us proof of their performance then it will help us to continue with them next year. They must please share this information. (LO Teacher, Primary School, Khayelitsha)

A major organisational challenge for these NGOs is the lack of cooperation from school staff and the conflict between teachers and coaches. Teachers often feel threatened by the coaches from NGOs and refuse them access to their classroom even though an agreement between the school and organisation exists. Furthermore, school staff often claim that the coaches are a distraction, interrupting their learning time and getting the children excited and noisy with the promise of exercise and sport, thereby hindering their academic focus:

The teachers think we will take their jobs and they see that the students like us. Sometimes they get angry with us. But we are not teachers so we cannot take their jobs. (Anonymous Coach)

Coaches also felt that teachers did not respect them, and they were undermined because of their age and culture. They argued 'having a white person with us will help because they are from a different culture' (Coaches, 2010), raising the issue of racial profiling. The coaches do have certificates as proof of their training, but as they cannot carry these with them everywhere they claimed it would be better to have an ID card showing their affiliation to the NGO and school.

Normally teachers are not present during the LO sessions conducted by the international NGO. Coaches claim this is beneficial because learners are more likely to open up and speak about sensitive issues if the teacher is absent. But on the other hand, the lack of an authority figure means the kids are often unruly and ill- disciplined, showing less respect to the younger, less 'official' coaches. Since teachers do not generally witness the sessions, they do not understand the value of the programme and regard it as something secondary to their classes. Coaches feel they are often viewed with suspicion and there is a perceived distrust from certain teachers.

Furthermore, there is a high turnover of coaches with many moving onto better employment. Given the organisation's investment in these coaches and the 
relationships they have built with learners, this high turnover does not bode well for sustainability. Teachers are a permanent part of the school system and it would make sense to include them, so that sport and physical activity are able to continue without the relevant NGO or coach, thereby creating long-term impacts.

Similarly to the organisational challenges expressed above, Clark et al. (2006) reported on the need for teacher education to assure sustainability of such programmes. This is especially important as teachers can provide answers to follow-up questions from students. However, Clark et al. (2006) also drew attention to the fact that teachers noted that students were more willing to discuss sensitive issues, such as sexual behaviour and drugs, when they were not present.

\section{Discussion}

The study suggests that NGOs face a variety of challenges using sport in schools. From the data gathered it would appear there is an urgent need for such organisations to formalise the relationship with schools which should ensure that these organisations and their staff are seen as a more integral part of the school day, and thus more likely to be accepted by teachers, who should have been briefed as to the service agreement between said school and NGO. A good working relationship between the management and ground staff of the school and NGO is desirable. The research indicates that there are pros and cons to working during school or after hours, and combining these two approaches would allow NGOs to reach the majority of learners and help schools act as community hubs in the afternoon. Providing regular training and support will keep school staff and coaches motivated and allow them to broaden their range of skills. Diversifying the range of sports available and linking these activities with academic subjects will allow the organisations to bridge the gap between the field and classroom.

Furthermore, involving teachers in the process is essential since any school activity should be educator driven*the study has shown that in instances where educators are not involved the programme is less likely to succeed. Therefore it is suggested that coaches work with the teachers as well as the children, since the teachers can then formalise this process and create structured school sport teams as well as link the lessons from these interventions to the regular academic curriculum.

However, there are issues with teachers attending LO sessions as learners may no longer feel comfortable sharing sensitive information. Furthermore, many coaches are inexperienced and unskilled and may not have the capacity to interpret sensitive information and provide mentoring and counselling to learners, or share this with teachers. Appointing external personnel to deliver LO classes at school creates confusion as it blurs the roles between educator and sports coach, and between classroom time and extra-mural activities. There are difficulties in this process, as detailed by Whipp et al. (2011) in their study on the outsourcing of PE at primary schools.

Sport and PE are an integral part of the school day and should assume an equal footing to other classes, whether these sport activities take place during LO or as 
extra-mural programmes. While most educators would agree to this in principle, it is obvious that the Department of Education has privileged academic achievement, especially literacy and numeracy, above sport given the poor pass rates across the country and the great disparities in the education system. As such, the benefits of sport and its contribution to health, social inclusion, school attendance, better discipline and academic achievement should be leveraged by relevant officials within the education system.

Government can play a role in this regard by raising the profile of sport and regarding it as an equal partner in the curriculum. According to teachers, the amount of administration has increased despite promises to the contrary, and this is centred on academic performance, with sport taking a back seat. With the marginalisation of $\mathrm{PE}$ in the curriculum, it is more important than ever that youth can partake in sports and physical exercise at schools. After this research was conducted, the South African Government finally reintroduced PE as a stand-alone subject ( 2 mandatory hours per week) in schools from 2012. This bodes well for the future.

It has become clear that partnering with government is a catch-22 situation for many civil society organisations as it may empower them with funding and resources but may limit their independence. While the two NGOs in this study have differing relationships with government, both organisations do realise the need to work with the state so as to improve their outputs and impact. Furthermore, working in unison with other organisations and stakeholders is likely to be more effective and sustainable than duplicating resources and programmes.

The analysis shows that sport-related NGOs operate within different policy models. The intervention policy model perceives NGOs as external agents with an independent intervention agenda. Embedded interaction with local authorities, if any at all, is perceived as a hindrance or complication of the NGO agenda. The arena model puts NGOs as mutual competitors in an arena of delivering services for development. NGOs not only need to compete for recognition, market share and funding at the donor side, but increasingly compete in direct service delivery in order to comply in the most efficient way with their objectives, donor expectations and to meet the increasing demand of evidence-based output. The pressure of competing in the same development arena may have two sided policy consequences. NGOs will try to be direct and straightforward in their objectives and methods, thereby underestimating the need to form structural links with local authorities and responsible institutions. Other NGOs will strengthen their relations with local authorities in order to improve their competitive position in the arena and to develop solid and durable growth for their programmes. In a partnership policy model, NGOs deliberately seek synergies with local authorities as basic policy steps to develop programmes. Although it will complicate issues and it is time consuming, the partnership policy model increases chances for efficiency and durability in the longterm and brings together practitioners from both sides of the field. 
It is important to note that these models are not necessarily exclusive and the NGOs may show characteristics from a number of models. Furthermore, no model can be definitively advocated as the best option since the context of each organisation and that of their environment is different. The models, at best, provide frameworks which organisations can adapt to their circumstances. In addition, while a partnership model is advocated, it is important to examine the nature of the partnership and ensure it is fair, equitable and just. Partnerships should be clearly conceptualised with a joint vision and agreed understanding of the roles and responsibilities within the relationship. Clear lines of communication and accountability are vital and organisations must ensure that any partnership helps, rather than hinders, their overall goals and objectives.

The socio-economic realities in post-apartheid South Africa affect many school sport and PE programmes. Outsourcing sport and physical activity to private and semi-private partners (Whipp et al., 2011) will become a growing and common practice and policy in such conditions. NGOs as well as market-driven commercial initiatives will enter this emerging field. However, outsourcing such programmes for reasons of feasibility and quality cannot imply the transfer of legitimacy and power from the educational environment to the external agent.

Finally, it is important to note that the work of NGOs is not sacrosanct. If these organisations do not contribute properly to, or align themselves with, greater development efforts, they may actually undermine the very communities they choose to work in. As with the use of sport as a development tool, NGOs need to operate in a certain environment and in a certain manner if their programmes are to be genuinely successful.

\section{Conclusion}

The observations in this study suggest that, particularly in a context of education, a partnership policy model of NGO work is to be preferred. Although partnership-seeking policy may delay direct interventions and may not be helpful to an organisation's competitive position at the outset, it appears crucial because education is one of the core responsibilities and tasks of local and national governments, supported by legislations and public administration. NGOs can lend support in this regard, but it is government who must take the lead, thus partnerships are vital. However, it is important to note that partnerships may bring their own set of challenges and may compromise the independence of civil society organisations, leaving NGOs in a deliberation over whether 'to partner or not to partner'. The power relations and parameters within the partnership will affect the outcome of any such partnership, and there a range of other possible variations.

The results from the field observation clearly indicate the need for a partnership policy model between NGOs and local authorities. Donors, monitoring and evaluation agencies and the public at large, as well as NGOs and the state themselves, need to understand that a partnership policy model for sport-related NGOs, although complicated and time consuming, is likely to be the most effective, 
sustainable and durable model of using sport as a vehicle for education. Having said this, one must recognise the complexity of relationships, and possible partnerships, and that like sports activity itself, partnering needs to occur under the right circumstances to be effective.

It is recognised that many NGOs operate externally in an arena policy model where they have to transmit their message and realise their objectives as they compete with other organisations for their market share. Yet, a call for a partnership model of interaction and cooperation between NGOs and the educational system at all policy levels and processes is heard. While organisations cannot simply implement a one size fits all policy or model, there are certain benefits to partnering with other stakeholders as long as the partnership is properly and fairly managed.

In conclusion, it is clear NGOs can support schools in South Africa to optimise their sports and physical activity programmes in the backdrop of a skewed apartheid legacy, a stagnating education system and a lack of sporting support from the government. However, they encounter many obstacles and would perform better by paying attention to the concerns of schools and coaches, and engaging with the state, other civil society organisations and community stakeholders to partner more effectively in the sports arena to create a level playing field for all. 


\section{References}

Amstrong, G. (2004) The lords of misrule: football and the rights of the child in Liberia, West Africa, Sport in Society, 7(3), 473-502.

Beutler, I. (2008) Sport serving development and peace: achieving the goals of the United Nations through sport, Sport in Society, 11(4), 359-369.

Bhorat, H., van der Westhuizen, C. \& Jacobs T. (2009) Income and non-income inequality in post- apartheid South Africa: what are the drivers and possible policy interventions? (Cape Town, University of Cape Town Development Policy Research Unit).

Cashmore, E. (1990) Making sense of sport (London, Routledge).

CIA, (2010) CIA - The world factbook-South Africa. Available online at:

https://www.cia.gov/library/publications/the-world-factbook/geos/sf.html (accessed 5 November 2009).

Clark, T. S., Kaufman, Z. A., Friedrich, G. K. \& Ndlovu, M. (2006) Kicking AIDS in Africa: soccer players as educators in adolescent-targeted HIV prevention, Harvard Health Policy Review, 7(2), 61-71.

Coaches (2010) Interview with Coaches at Grassroots Soccer on May 28, 2010, Cape Town.

Coalter, F. (2010) The politics of sport-for-development: limited focus programmes and broad gauge problems? International Review for the Sociology of Sport, 45(3), 295-314.

Cooper, A. (2009) Barriers to the implementation of Extra-Murals. Unpublished paper (Cape Town, Extra Mural Education Project).

Cronbach, L. J. (1975) Beyond the two disciplines of scientific psychology, American Psychologist, 30, 116-127.

Department of Basic Education \& Sport and Recreation South Africa, (2011) Memorandum of understanding between the Department of Basic Education and Sport and Recreation South Africa on An Integrated School Sport Framework, Pretoria.

Draper, C. et al. (2010) HealthKick: a nutrition and physical activity intervention for primary schools in low-income settings, BMC Public Health, 10, 398-410.

Extra-Mural Education Project, (2009) South Africa. Available online at: http://www.emep.org.za/index.php?option $=$ com_content\&view $=$ article\&id $=4$ \&Itemid=3 (accessed 12 December 2009).

Flintoff, A. (2003) The school sport co-ordinator programme: changing the role of the PE teacher? Sport, Education and Society, 8(2), 231-250.

Grassroot Soccer, (2010) South Africa. Available online at: http://www.grassrootsoccer.org/where- we-work/south-africa/ (accessed 15 July 2010).

Hardman, K. \& Marshall, J. (1999) Worldwide survey of the state and status of school PE: summary of Findings, ICSSPE.

Hayburst, L. M. C. \& Frisby, W. (2010) Inevitable tensions: Swiss and Canadian sport for development NGO perspectives on partnerships with high performance sport, European Sport Management Quarterly, 10(1), 75-96.

Houlihan, B. (2000) Sporting excellence, schools and sports development: the politics of crowded policy spaces, European PE Review, 6, 171. 
Houlihan, B. \& Green, M. (2006) The changing status of school sport and PE: explaining policy change, Sport, Education and Society, 11(1), 73-92.

Irurzun-Lopez, M. \& Poku, N. (2005) Pursuing African AIDS governance: consolidating the response and preparing for the future, in: A. S. Patterson (Ed.) The African state and the AIDS Crisis (Aldershot, Ashgate Publishing), 219-230.

Kaufman, Z. (2009) Interview with Head of Monitoring and Evaluation at Grassroots Soccer on October 26, 2009, Cape Town.

Keim, M. (2010) Sport as opportunity for community development and peace building in South Africa, International Conference on Sport \& Development, University of Western Cape, Cape Town, 1 September 2010.

Keim, M. (2009) Overcoming challenges based on a collaborative approach, The Forum on Productive Youth Development through Sport in Africa (Nairobi, United Nations Office).

Kidd, B. (2008) A new social movement: sport for development and peace, Sport in Society, 11(4), 370-380.

Lindsey, I. \& Banda, D. (2011) Sport and the fight against HIV/AIDS in Zambia: a 'partnership approach'? International Review for the Sociology of Sport, 46(1), 90-107.

Macdonald, D., Hay, P. \& Williams, B. (2008) Should you buy? Neo-liberalism, neo-HPE, and your neo-job, New Zealand Physical Educator, 41(3), 6-13.

Merriam, S. B. (1998) Qualitative research and study applications in education (San Francisco, Jossey-Bass Education Series and Jossey-Bass Higher Education Series).

Pillay, U., Tomlinson, R. \& Bass, O. (2009) Development and dreams: the urban legacy of the 2010 football world cup (Cape Town, HSRC Press).

United Nations, (2003) Sport for development and peace: towards achieving the millennium development goals (New York, United Nations).

United Nations Inter-Agency Task force on Sport Development and Peace, (2003) Sport for development and peace: towards achieving the millennium development goals (Geneva, United Nations).

Van Eekeren, F. (2006) Sport and development: challenges in a new arena, in: Y. Auweele C. van den Malcolm \& B. Meulders (Eds) Sport and development (Leuven, Lannoo), 19-34.

Van Eyken, S. (2010) A study of NGOs in the field of sport and development. Unpublished Master thesis, Katolieke Universiteit, Leuven, Belgium.

Webb, D. (2004) Legitimate actors? The future role for NGOs against HIV/AIDS in sub-Saharan Africa, in: N. Poku \& A. Whiteside (Eds) The political economy of AIDS in Africa (Aldershot, Ashgate Publishing), 19-32.

Whipp, P. R., Hutton, H., Grove, J. R. \& Jackson, B. (2011) Outsourcing PE in primary schools: evaluating the impact of externally provided programmes on generalist teachers, Asia Pacific Journal of Health, Sport and PE, 2(2), 67-78.

Youth Aids, (2010) Our Mission. Available online at: http://projects.psi.org/site/PageServer?pagename=OurMission_nr (accessed 5 July 2010). 